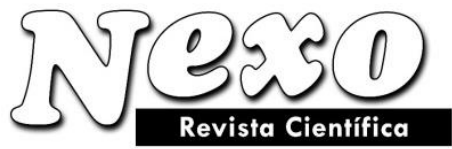

\title{
Usability evaluation of mobile devices user interface
}

\section{Evaluación de usabilidad de la interfaz de usuario de dispositivos móviles}

\author{
Wajdi Aljedaibi*, Reem Mohammed Bashmail
}

Computer Science Department, Faculty of Computing and Information Technology, King Abdulaziz University, Jeddah, Saudi Arabia

waljedaibi@kau.edu.sa

(recibido/received: 21-mayo-2021; aceptado/accepted: 12-agosto-2021)

\begin{abstract}
Designs of mobile human-computer interaction (HCI) target to create interactive and familiar products that are simple and interested to use. The mobile devices such as smartphones or tablets are becoming more and more popular and may to some extent replace the desktop computer and laptop as the most prominent hardware for HCI. This article presents a technical background for this area, the survey of selected user interface (UI) usability principles of today's mobile devices design and user's interaction for evaluation purposes. The experiment conducted through a questionnaire having four elements related to usability, i.e. usefulness, ease of use, ease of learning, and satisfaction. Furthermore, the evaluation process performed using quantitative analysis to understand and investigate the participants' responses based on the Likert scale. The results suggested that most of the participants show a high level of satisfaction towards mobile devices and its interface. The attained level of satisfaction for each element was recorded as $63 \%$ for usefulness, $71 \%$ for ease of learning, $78 \%$ for ease of use and $70 \%$ for satisfaction. The collected results can guide the developers and mobile companies to understand the satisfaction level of mobile users. It will also help them to enhance the design and user interface of mobile applications based on usability and flexibility.
\end{abstract}

Keywords: HCI, Mobile device, Mobile interactivity, mobile interface, interaction design.

\section{RESUMEN}

Los diseños de interacción humano-computadora (HCI) móvil tienen como objetivo crear productos interactivos y familiares que sean simples e interesados en usar. Los dispositivos móviles, como teléfonos inteligentes o tabletas, se están volviendo cada vez más populares y, en cierta medida, pueden reemplazar a la computadora de escritorio y la computadora portátil como el hardware más destacado para HCI. Este artículo presenta un trasfondo técnico para esta área, la encuesta de principios de usabilidad de la interfaz de usuario (UI) seleccionados del diseño de dispositivos móviles de hoy y la interacción del usuario con fines de evaluación. El experimento se realizó a través de un cuestionario que tiene cuatro elementos relacionados con la usabilidad, es decir, utilidad, facilidad de uso, facilidad de aprendizaje y satisfacción. Además, el proceso de 
evaluación se realizó mediante análisis cuantitativo para comprender e investigar las respuestas de los participantes en función de la escala Likert. Los resultados sugirieron que la mayoría de los participantes muestran un alto nivel de satisfacción hacia los dispositivos móviles y su interfaz. El nivel de satisfacción alcanzado para cada elemento se registró como $63 \%$ para la utilidad, $71 \%$ para la facilidad de aprendizaje, $78 \%$ para la facilidad de uso y $70 \%$ para la satisfacción. Los resultados recopilados pueden guiar a los desarrolladores y las empresas de telefonía móvil a comprender el nivel de satisfacción de los usuarios de dispositivos móviles. También les ayudará a mejorar el diseño y la interfaz de usuario de las aplicaciones móviles basadas en la usabilidad y la flexibilidad.

Palabras clave: HCI, dispositivo móvil, interactividad móvil, interfaz móvil, diseño de interacción.

\section{INTRODUCTION}

In mid-1980s, The HCI term has been adopted. In 1992 Association for Computing Machinery (ACM) define the meaning of HCI, which deals with overall design and implementation of a computer system and how it interacts with human (Hewett et al., 1992). There is a set of principles that should be considered when design a mobile service or system such as the context of use, consistency, learnability, flexibility, system feedback and support. When designing any interactive system, the platform in which the services and system will be implemented must be known. For example, people will use those application and devices in static or dynamic environment. In addition, the users may find the situation where network connection is not good as the network signals vary from location to location. The reason behind the network disturbance is because of dynamic movement like sitting in a car or walking down the streets. This will cause the difficulties in performing task and will make possible delay in work submission.

Another interface characteristic is to provide consistency while modifying the system (Ji et al., 2006). Consistency means that the interface must be the same as the users already had experience while working on the previous interface. It is not a good idea to design completely a new system with new interface, until not required. The best way is to modify the system with the new services, within the same structure as before. It should not require more time from the users to learn the use of new interface. In human computer interaction design, this technique is known as easy to learn and use.

In addition, the user interface must have flexibility in use. The term flexibility is focused on the way the people work and interact with mobile devices. The interface needs to be developed based on the potential user's requirement. While keeping in mind that different users have different opinion. Here the developers require to be focused on general and common ideas, which can fit with maximum of user's and organization's requirements. Therefore, the system interface modification should be done by having proper feedback from the users. In addition, flexibility is also commonly relating with the problems associated with the list of services and overall hierarchy of the menus. Regular changes in hierarchy will cause the delay in user's work and it will be difficult for the users to reach on the specific location (Brewster, 2002).

Usability is a quality attribute that assesses those principles. It is a fundamental attribute in the design that must be focused during software development. The International Standards 
Organization (ISO) published a standard on usability (ISO/TC 159/SC 4 Ergonomics of humansystem interaction (Subcommittee), 1998). It stated that efficient and satisfying system can build by fulfilling the usability requirements. Those requirements allow the users to interact with the system in easy and friendly environment. It further described that effectiveness known as usefulness of the system for which it was developed. Whereas the efficiency is related to the performance of the system in executing the tasks. Finally, the satisfaction describes about the user's feedback on the system while use and learning of the system.

\section{MATERIALS AND METHODS}

The ISO Standard (International Organization for Standardization, 1999) on human-centred design described the four phases should be performed during the planning of a human-centred design system:

- Identify and investigate the application environment.

- Identify user and company's requirements.

- Generating a good design as a solution.

- Testing the design according to the requirements.

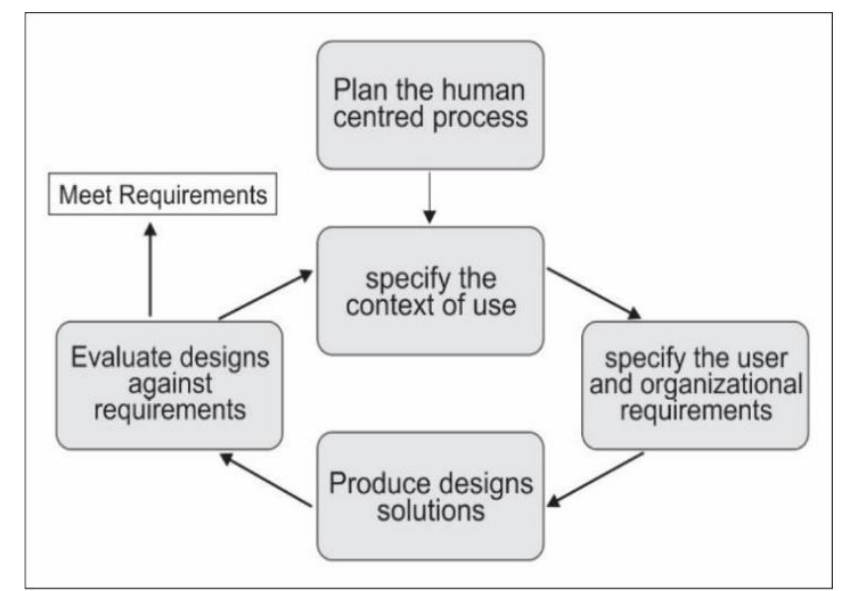

Figure 1. The interdependence of user centred design activities (International Organization for Standardization, 1999)

The techniques defined for the process of building effective interface design is shown in Figure 1 shows. As seen in the Figure 1, that the evaluation is an essential part of a human-centred design process. According to (Addison-Wesley, 1994) there are four major factors behind evaluation of system's usability:

1. To assess multiple prototype.

2. To analyze and investigate that application matching with usability requirements.

3. To assure that application meet with the industry standards.

4. To identify the relationship between users and technology in reality.

Usability testing is one of the major techniques used for system evaluation from use and learning perspectives. The technique consists of gathering the data from the users while using the system 
and performing some activities. This will help to study and investigate the usability of a system from user's point of view (Dix et al., 2000). Another case study conducted by (Jokela et al., 2006) to highlight the improvement in the project where the quantitative usability requirements were used and proved as appropriate. The used methods were not following the previous famous usability methods. They fully advise the use of measurable usability requirements (Jokela et al., 2006).

According to (), "checklist of usability process can be divided into three stages, In first stage, the materials of prior "style guide" are gathered and examined to gain user interface "UI" components that form the mobile device UI. When components of UI are extracted, a hierarchical organization of those component is structured. This hierarchy constructs the foundation of the checklist evaluation, which will assist to enhance efficiency of heuristic assessment process. In the next phase, the survey on usability issues need to be conducted. Survey results are organized and considered the major usability principles, which need to be tested in usability interface (UI) design process for mobile devices. Principles are further selected, modified, and combined into a structure ensuring the categorization of usability principles. This manipulation conducted using particular standards. In stage 3, through comparison of the pairwise, UI elements from stage 1 and usability principles from stage 2 are compared. Then, for one UI element, relevant questionnaire sentences developed to compare the usability principles. The questionnaire was developed to be understandable and applicable for the experts and programmers (Ji et al., 2006).

The Scientific World Journal (Yáñez Gómez et al., 2014) presented a collection of heuristic evaluation (HE). In this study, specifically the items were reorganized for mobile devices interfaces. The primary work and test conducted in this study, highlighted that the proposed HE checklist is appropriate tool for programmers and designers, where the prior knowledge of usability is not required. Furthermore, (Nilsson, 2009) proposed 6 types of problems related to mobile application design development. The problems mentioned as "screen environment, flexible user interface, dealing with input, no use of stylus, no proper guidelines and complex in understanding". This research used and validated the design patterns using questionnaire on two different tutorials.

The paper is organized as follows. The next section describes Likert questionnaire followed by the methodology section. The results presented with the help of diagrams and tables. Later on a brief discussion presented using the generated results. Finally, the paper concluded by presenting the final output of this research followed by future work.

\section{Mobile devices}

A mobile or portable device used to perform the task anytime and from anywhere. It is easy to carry those devices, where it provides the facilities to execute your tasks with no restriction. The portable gadgets are powerful devices, and it allow to work as same as performing the work on other computing devices such as; personal computers. Nowadays, the internet facilities and electronic services are not restricted to desktop machine only, but a user can perform those tasks using smartphone and other portable devices easily. Due to this, the developers have more responsibilities to develop computer system, which are adaptable and applicable on portable devices as well.

Mobile devices consist on distinct hardware specifications as compared with home and office personal machines. Most of the times, the screen size is smaller, but easy in use and flexible in 
switching over to other applications. The landscape and portrait mode are other features available in mobile devices, which makes user to work as per their requirements. Application program interface (API) like geolocation or orientation are not very common for personal computers or not very helpful, but for mobile devices it is popular and provide new way for interaction (Corporation, 2020). In general, the focus of designing the user interface of mobile devices is to make it easy to learn, understandable, and develop it as per user's requirements. The interface of any mobile application must consider less attention from the users, minimize the keystrokes, and minimum set of functions should be task oriented. This functionality is supported by Mobile enterprise application platforms or integrated development environments. The past researches suggested that, mobile devices have been evaluated from different perspectives and in different scenario such as for healthcare architecture (Liu et al., 2019), privacy and usability in mobile health systems (Katusiime \& Pinkwart, 2019), and measuring the visual screen time for daily routing mobile applications (Bâce et al., 2020).

\section{Likert scales and data analyses}

The questionnaire is a standard tool used for collecting the data in any field of research. It is one of the ways to get the user's insight about product, system, or service. The questionnaire technique is helpful to attain the user's mind reflection on a selected item. In this research, the Likert scale questionnaires used for collecting the user's feedback on different attributes of the usability testing (Likert, 1932). In this kind of questionnaire, the questions asked from the participants to indicate the degree of agreement and disagreement with the specific question or quality of the system. The strategy here is to get the responses for each item designed in the questionnaire and accumulate the average score. The collected score from the participants can reflect their mindset and satisfaction with the system. (USE) The Usefulness, Satisfaction, and Ease of Use questionnaire - shown in Figure 2- was developed by (Lund, 2001) and can be used to evaluate any interface. It is a nonproprietary 30-item questionnaire that measures usefulness, satisfaction, and ease of use of an interface using a seven-point Likert agreement scale (Johnson et al., 2011) e.g. from 1 (totally disagree) to 7 (totally agree) as shown in Figure 3. Users were invited to rate agreement with the statements, ranging from strongly disagree to strongly agree. Many forms of the questionnaires were applied to evaluate user perspectives towards a variety of customer products (Stecker et al., 2019; Palin et al., 2019). Factor analyzes following each study proposed that users be evaluating the products primarily using three dimensions, Usefulness, Satisfaction, and Ease of Use. In paper (Chung \& Sahari, 2015), it is recognized that the USE questionnaire have the highest proportion of measurements upon experiential domain compared to other questionnaires.

"The common way to report on a Likert scale is to get the sum of the values of each chosen option and generate a score for each respondent. This score is then used to represent a particular feature. This is quite useful for evaluating a respondent's opinion of important purchasing, product, or satisfaction features. The scores will be used to create a chart of the distribution of evaluation across the population. For further analysis, the score mean can tabulated with contributing factors" (Surveygizmo, 2012).

\section{Research Problem}

The above discussion highlights the importance of usability and efficiency of mobile devices and applications. Customer satisfaction is a critical factor for mobile companies and mobile application 
developers. Therefore, this paper aims to investigate the satisfaction level of the mobile users while using mobile devices from usability and learning perspectives.

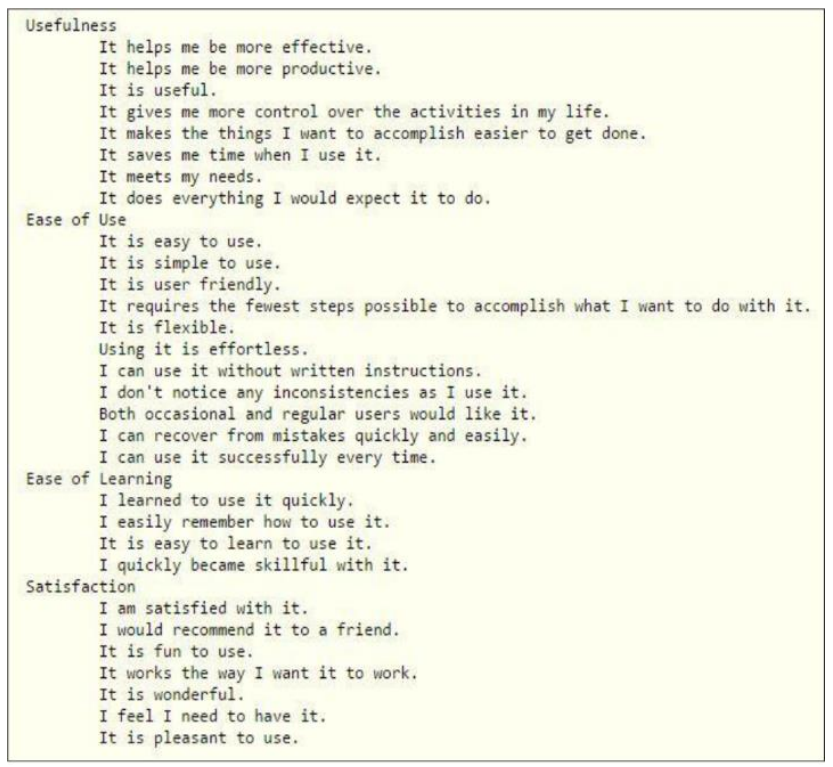

Figure 2. USE questionnaire (Lund, 2001)

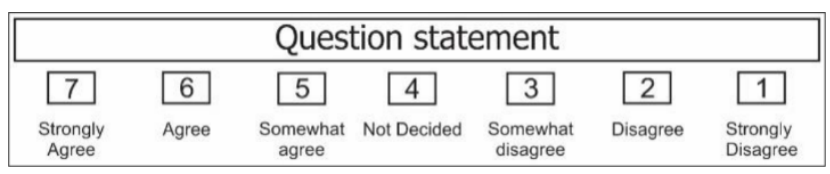

Figure 3. Scoring for statements in a USE- questionnaire

This study collected data and share the views from the students studying in public university of Saudi Arabia. The study designed to understand the user satisfaction levels of a mobile device's interface. Participants consisted of 35 (80\% female, 20\% male), their age is between (22 - 35) years. They fill out the web-based USE questionnaire (seven-point Likert rating scales) as presented in Appendix-A. The USE focuses on the interface usability by the evaluation of particular aspects (usefulness, ease of use, ease of learning and satisfaction).

"The Likert scale common way to report is to sum the values of each selected option and create a score for each respondent. Then, this score is used to evaluating a respondent's opinion of satisfaction features. The scores will be used to create a chart of the distribution of opinion across the population. For further analysis, score will be tabulated with details" (Surveygizmo, 2012).

\section{RESULTS AND DISCUSSION}

As discussed above, this study focused on measuring the behavior of mobile users from usability, learning, and satisfaction context. Based on the collected data, the overall views of the participants were reasonably positive towards the use of mobile devices, the flexibility provided in the mobile applications, and user-friendly interfaces. Apart from the excessive launching of new mobile applications every day, the results have shown great satisfaction in using mobile devices. 
The summary of the collected data shown in Figure 4, which highlights that most of the participants tend towards satisfaction with the usability of the user interface through positive approval of the questionnaire's statements. The figure is representing the association between two attributes; the horizontal axis that is showing the level of acceptance for each element, while the vertical axis emphasizing on a number of participants. Altogether there were four elements asked in the questionnaire (usefulness, ease of learning, ease of use, and satisfaction). The figure pointing out that, in most of cases the level of agreement towards each factor is recorded as high. On the whole, the number of participants agreed on "usefulness", "ease of learning", "ease of use", and "satisfaction", were 175, 274, 109, and 171 respectively. The evidence shows satisfaction level is far better than disagreement, which proved that the users are strongly dependent and satisfied by mobile devices and applications.

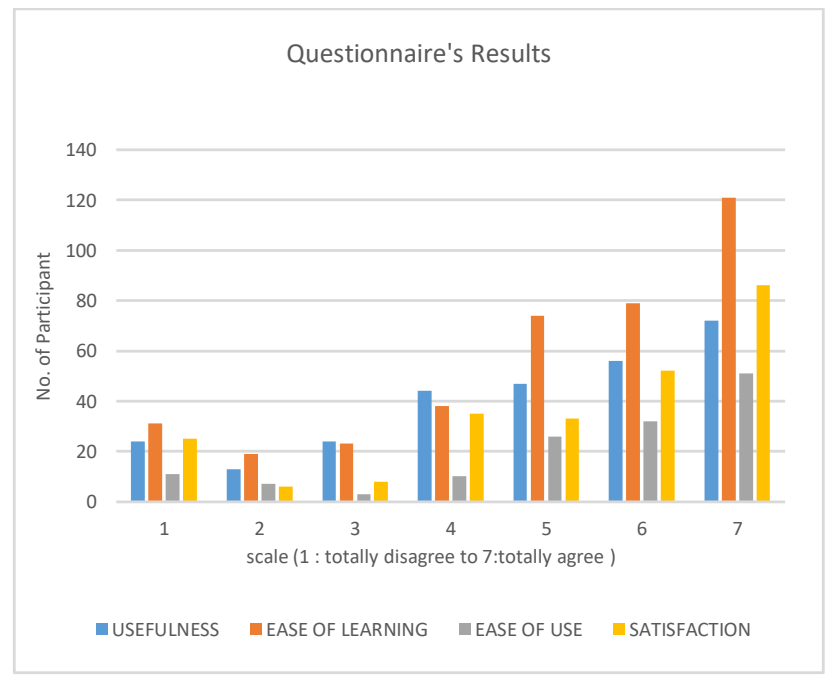

Figure 4. Questionnaire's results

Furthermore, the reflection of the collected data is showing in Table 1. The participants who strongly agreed have the highest percentage than the other groups. If we take into consideration all agreement levels, the rate of satisfaction will be clear for understanding. As evidence $63 \%$ for usefulness, $71 \%$ for ease of learning, $78 \%$ for ease of use and $70 \%$ for satisfaction is measured from the participant's responses. Conversely, there are some responses, which require proper attention from the mobile manufacturer and developers. According to the data, the percentage of disagreement/avoidance for "usefulness", "ease of learning", "ease of use", and "satisfaction", got as $37 \%, 31 \%, 22 \%, 30 \%$ respectively. The percentage is fairly low and needs a possible improvement in mobile devices. It further shows that still, some users are not fully satisfied with the current making and designing of mobile devices. In addition, the understanding level of the questions and participant's interest could be a factor behind low percentage. Finally, according to the reviewer's point of view, the mobile devices do not really feel fun for them, nor they felt that they would really need it. The response details for each element and respective questions is further illustrated in Figures 5-8. 
Table 1. Responses to the USE questionnaire

\begin{tabular}{|c|c|c|c|c|}
\hline \multirow{2}{*}{$\begin{array}{c}\text { Strongly } \\
\text { Disagree }\end{array}$} & USEFULNESS & $\begin{array}{c}\text { EASE OF } \\
\text { LEARNING }\end{array}$ & EASE OF USE & SATISFACTION \\
\cline { 2 - 5 } & 24 & 31 & 11 & 25 \\
\hline \multirow{2}{*}{ Disagree } & 13 & $8 \%$ & $8 \%$ & $10 \%$ \\
\cline { 2 - 5 } & $5 \%$ & 19 & 7 & 6 \\
\hline $\begin{array}{c}\text { Somewhat } \\
\text { Disagree }\end{array}$ & 24 & 23 & $5 \%$ & $2 \%$ \\
\hline $\begin{array}{c}\text { Not } \\
\text { Decided }\end{array}$ & $4 \%$ & $6 \%$ & $2 \%$ & $3 \%$ \\
\cline { 2 - 5 } Somewhat & $16 \%$ & $10 \%$ & $7 \%$ & $35 \%$ \\
\cline { 2 - 5 } Agree & $17 \%$ & $19 \%$ & $19 \%$ & $33 \%$ \\
\hline Agree & 56 & 79 & 32 & 52 \\
\cline { 2 - 5 } & $20 \%$ & $21 \%$ & $23 \%$ & $21 \%$ \\
\hline \multirow{2}{*}{$\begin{array}{c}\text { Strongly } \\
\text { Agree }\end{array}$} & 72 & 121 & 51 & 86 \\
\cline { 2 - 5 } & $26 \%$ & $31 \%$ & $36 \%$ & $35 \%$ \\
\hline
\end{tabular}

The below section provides the graphical representation to highlights the responses collected for each factor used in the questionnaire. Figure 5 demonstrates the summary of responses collected for the factor "usefulness". There was total of eight questions asked to assess the performance and satisfaction of the participant for the usefulness of the mobile devices. It can be clearly identified from this figure that question number 8 got the lowest level of agreement. The question was asking about the "mobile devices can do everything I would expect to do". The question was highly negated by the participants, which emphasizes that these devices still need some improvement in the execution of some tasks.

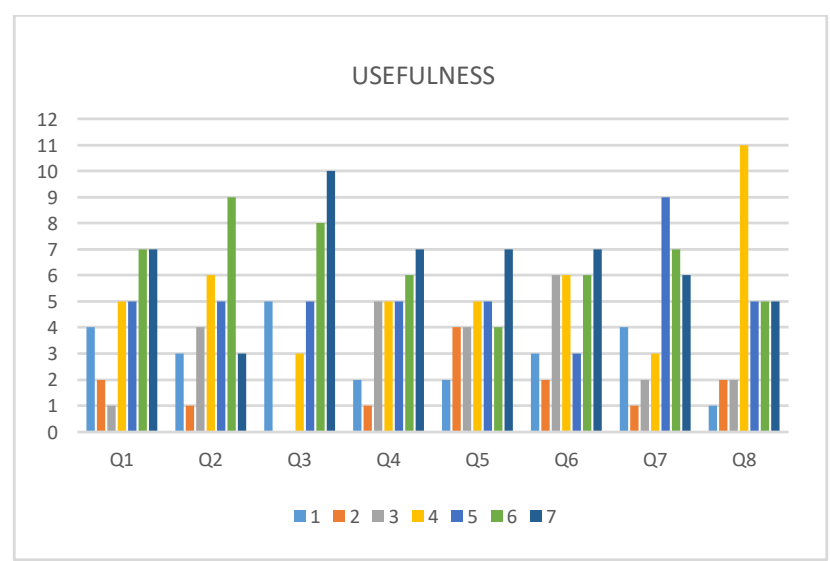

Figure 5. Q1-Q8 usefulness responses

Figure 6 provides the specification of the questions associated with "Ease of Use". This dimension investigated with the help of 11 distinct questions. The responses to the questions asked for this dimension have mixed properties. However, the lowest agreed response received for the question number 18 . This question was belongs to "the recovery of mistakes can be done easily and quickly". Surely, the less agreement is associated only with the sample users, but it gives a confirmation that respondents are not thinking that recovery of the mistakes is easy while using mobile devices. In 
contrast, the highest agreed components for this factor was question number 10, which is about the simplicity of mobile devices. The people suggest that these devices are simple in use.

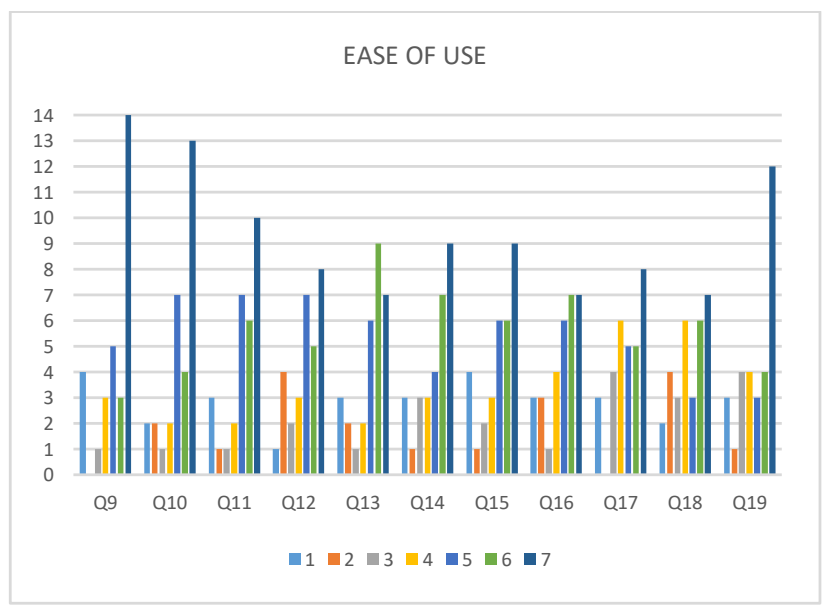

Figure 6. Q9-Q19 Ease of use responses

The next figure in this section is Figure 7 illustrating the responses collected for the entity "Ease of Learning". As shown in the figure, this entity assessed through 4 questions. Overall, the percentage of agreeing is high for all questions asked for this entity. It demonstrates that people are much in favor of mobile devices that are easy in learning, and do not require more effort to work on it.

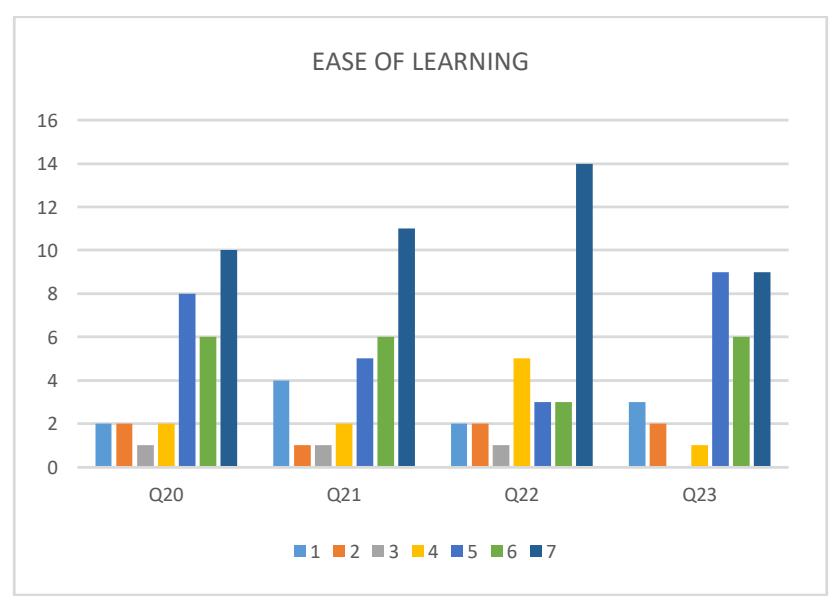

Figure 7. Q20-Q23 Ease of learning responses

Finally, the last figure in this section is showing the summary of the variable known as "satisfaction" as shown in Figure 8. There were 7 questions asked for measuring this variable related to pleasant in use and working environment. The group of participants responded positively in agreeing to the questions and pleased in using mobile devices. The high number of participants voted for question number 24 , which is related to the satisfaction level with the mobile devices. 


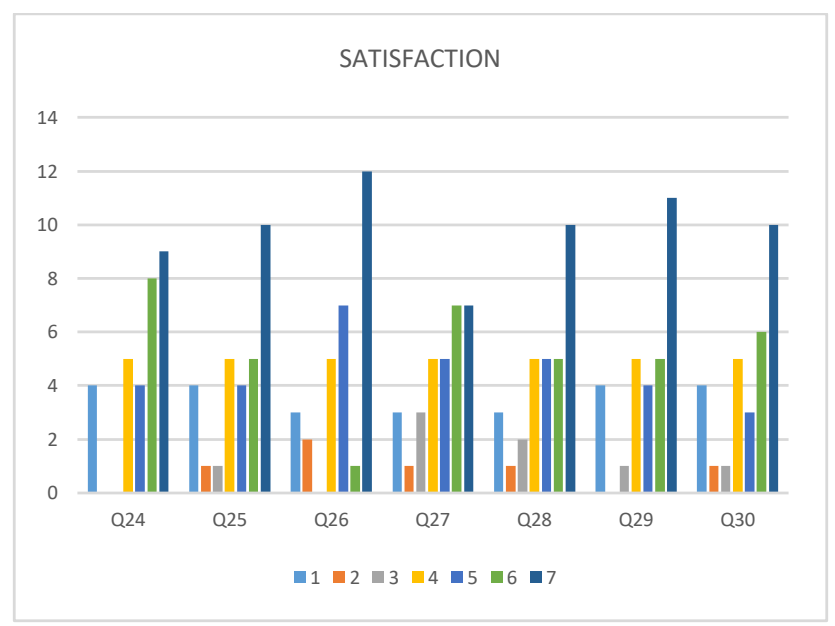

Figure 8. Q24-Q30 Satisfaction responses

\section{CONCLUSION}

Mobile devices changed the way people communicate with each other. The advancement in this field is allowing the users to have flexible environment with most of the online services available on mobile devices. The latest mobile devices include smart phones, tablets, and other portable devices. The latest development in mobile devices also providing new research ideas based on the usability perspective. The USE survey for user interface satisfaction helps us to get a more detailed understanding of the potential problems of the mobile devices. This study measures the user satisfaction on four levels: usefulness, ease of use, ease of learning and satisfaction. Our results indicate that the mobile devices interface is relevant and interesting to the users.

\section{CONFLICT OF INTEREST}

The authors confirm that the information provided in the article does not contain a conflict of interest.

\section{REFERENCES}

Addison-Wesley, Human-Computer Interaction, 1994.

Bâce, M., Staal, S., \& Bulling, A. (2020, April). Quantification of Users' Visual Attention During Every day Mobile Device Interactions. In Proceedings of the 2020 CHI Conference on Human Factors in Computing Systems (pp. 1-14).

Brewster, S. (2002). Overcoming the lack of screen space on mobile computers. Personal and Ubiquitous Computing, 6(3), 188-205.

Chung, T. K., \& Sahari, N. (2015). Utilitarian or experiential? An analysis of usability questionnaires. International Journal of Computer Theory and Engineering, 7(2), 167-171.

Corporation, M. (2020). Mobile Web Development. Available: https://developer.mozilla.org/enUS/docs/Web/Guide/Mobile, last accessed date $19^{\text {th }}$ January.

Dix, A., Finlay, J., Abowd, G. D., \& Beale, R. (2000). Human-computer interaction. Harlow ua. 
Hewett, T. T., Baecker, R., Card, S., Carey, T., Gasen, J., Mantei, M., ... \& Verplank, W. (1992). ACM SIGCHI curricula for human-computer interaction. ACM.

International Organization for Standardization. (1999). Human-centred design processes for interactive systems. International Organization for Standardization.

ISO/TC 159/SC 4 Ergonomics of human-system interaction (Subcommittee). (1998). Ergonomic Requirements for Office Work with Visual Display Terminals (VDTs).: Guidance on Usability. International Organization for Standardization.

Ji, Y.G., Park, J.H., Lee, C., \& Yun, M.H. (2006). A Usability Checklist for the usability evaluation of mobile phone user interface," international journal of human-computer interaction.

Johnson, C. M., Johnston, D., \& Crowle, P. K. (2011). EHR usability toolkit: A background report on usability and electronic health records. Rockville, MD: Agency for Healthcare Research and Quality.

Jokela, T., Koivumaa, J., Pirkola, J., Salminen, P., \& Kantola, N. (2006). Methods for quantitative usability requirements: a case study on the development of the user interface of a mobile phone. Personal and Ubiquitous computing, 10(6), 345-355.

Katusiime, J., \& Pinkwart, N. (2019). A review of privacy and usability issues in mobile health systems: Role of external factors. Health informatics journal, 25(3), 935-950.

Likert, R. (1932). A technique for the measurement of attitudes. Archives of psychology, 22, 55.

Liu, P., Fels, S., West, N., \& Görges, M. (2019). Human Computer Interaction Design for Mobile Devices Based on a Smart Healthcare Architecture. arXiv preprint arXiv:1902.03541.

Lund, A. M. (2001). Measuring usability with the use questionnaire12. Usability interface, 8(2), 3-6.

Nilsson, E. G. (2009). Design patterns for user interface for mobile applications. Advances in engineering software, 40(12), 1318-1328.

Palin, K., Feit, A. M., Kim, S., Kristensson, P. O., \& Oulasvirta, A. (2019, October). How do people type on mobile devices? Observations from a study with 37,000 volunteers. In Proceedings of the 21st International Conference on Human-Computer Interaction with Mobile Devices and Services (pp. 1-12).

Stecker, M., Nicolay, R., \& Martens, A. (2019, July). HCI Design for Mobile Devices with a Sensor System for Performance Diagnostic in Sports. In International Conference on Human-Computer Interaction (pp. 259-264). Springer, Cham.

Surveygizmo. (2012). Likert Scale - What is it? When to Use it? How to Analyze it?, 25-5.

Yáñez Gómez, R., Cascado Caballero, D., \& Sevillano, J. L. (2014). Heuristic evaluation on mobile interfaces: A new checklist. The Scientific World Journal, 2014. 